\title{
PHÂN TÍCH Cơ CẤU CHI PHÍ KHÁM CHỮA BỆNH BẢO HIỂM Y TẾ CHI TRẢ TẠI BỆNH VIỆN ĐA KHOA TỈNH LẠNG SƠN NĂM 2019
}

\section{TÓM TẮT}

Đặt vấn đề: Phân tích cơ cấu chi phí khám chữa bệnh bảo hiểm y tế (BHYT) tại cơ sở khám chữa bệnh giúp cơ quan quản lý là bảo hiểm xã hội $(\mathrm{BHXH})$ trong việc quản lý nguồn kinh phí BHYT, phát hiện tồn tại trong công tác khám chữa bệnh thông qua khoản mục chi. Muc tiêu của nghiên cứu là mô tả cơ cấu chi phí khám chữa bệnh theo một số chương bệnh có chi phí cao để đinh hướng trong công tác quản lý. Đối tượng và phương pháp: 35.239 phiếu thanh toán của bênh nhân đển khám và điều trị năm 2019 tai bệnh viện đa khoa tỉnh Lạng sơn lưu tại BHXH tỉnh. Phương pháp nghiên cứu: mô tả cắt ngang. Kết quả: 35.239 bệnh nhân đến khám và điêu trị tại bệnh viện gồm 21 chương bệnh. Tỷ lệ bênh nhân được chỉ đinh xét nghiệm là 98,3\%. Chi phí tiền giường cao nhất (chiếm 33,6\%); tiền phẫu thuật, thủ thuật chiếm 23,7\%; tiền thuốc, dịch truyền chiếm $17,6 \%$. Chi phí trung bình/đợt điều trị/bệnh nhân cao nhất là bệnh hệ thân kinh (2,81 triêu đồng). Ba kháng sinh có chi phí cao nhất là kháng sinh cephalosporin thế hê 3 (ceftizoxime; ceftriaxone) và thế hê 4 (cefepime). Kết luận: Chi phí tiền giường cao trong tổng chi phí khám và điều tri, thuốc kháng sinh cephalosporin thế hê 3 và thế hệ 4 có chi phí cao trong chi phí tiền thuốc, dich truyển.

\section{SUMMARY \\ HEATHCARE EXPENDITURE ANALYSIS OF LANG SON GENERAL HOSPITAL IN 2019}

Background and Objectives: Analyse of healthcare expenditure covered by the insurance within a hospital can help the management agency in managing the health insurance funds, finding existing problems in medical examination and treatment. This study aims to describe the expenditure structure by high-spending disease groups to build management plans. Methods: $\mathbf{3 5 2 3 9}$ payment slips of patients at Lang Son General Hospital in 2019 which stored at the provincial social insurance agengy were collected. Cross sectional study design was used. Results: 35239 patients were divided into 21 disease groups. The proportion of patients indicated to medical tests was $98,3 \%$. The highest cost was hospital bed, accounted for $33,6 \%$, the costs for surgery and procedures accounted for $23,7 \%$, the costs for medicine and infusion accounted for $17,6 \%$. The average cost per course per patient was 2,81 million

${ }^{1}$ Trường Đại học Dược Hà Nội

${ }^{2}$ Bảo hiểm xã hôi tỉnh Lang Sơn

Chiu trách nhiệm chính: Nguyễn Thị Thanh Hương

Email: thanhhuong.duochn@gmail.com

Ngày nhân bài: 18.01.2021

Ngày phản biện khoa học: 18.3.2021

Ngày duyệt bài: 29.3.2021

\section{guyễn Thị Thanh Hương ${ }^{1}$, Hứa Quang Thành ${ }^{2}$}

VND. The three antibiotics with the highest cost were the $3^{\text {rd }}$ generation cephalosporin (ceftizoxime, ceftriaxone) and $4^{\text {th }}$ generation (cefepime).

Keywords: cost, Lang Son, hospital.

\section{I. ĐĂT VẤN ĐỀ}

"Hướng tới thực hiện bao phủ chăm sóc sức khỏe và bảo hiểm y tế toàn dân" đã được đề cập trong Nghị quyết số 20-NQ/TW ngày 25/10/2017 của Ban Chấp hành trung ương Đảng khóa XII về Tăng cường bảo vệ, chăm sóc sức khỏe nhân dân trong tình hình mới ${ }^{[3]}$. Hiện nay số người tham gia BHYT là 87,93 triệu người với tỷ lệ bao phủ là $90,85 \%$ dân số. Tại Lạng Sơn, tính đến tháng 10/2019 có tỷ lệ bao phủ bảo hiểm y tế là $97,3 \%$ với số người tham gia BHXH tự nguyên là 8.670 người ${ }^{[5]}$. Hàng năm $\mathrm{BHXH}$ đã chi trả chi phí khám chữa bệnh theo quy định cho các đối tượng tham gia BHYT đi khám và điều trị. Nhằm nâng cao công tác quản lý chi trả cho đối tượng tham gia BHYT, đồng thời phát hiênn những tồn tại trong công tác khám và điều trị tại cơ sở khám chữa bệnh thông qua phân tích cở cấu chi phí chi trả khám chữa bệnh là cần thiết.

Kết quả khảo sát cớ cấu chi phí khám chữa bệnh BHYT tại bệnh viện đa khoa huyện Yên Châu, tỉnh Sơn La năm 2018 cho thây, với tổng chi phí khám chữa bệnh là 21,88 tỷ đồng thì tiền giường chiếm tỷ lệ cao nhất 40,93\%; tiền thuốc, dịch truyền đứng thứ hai với $33,73 \%[2]$.

Bệnh viện đa khoa tỉnh Lạng Sơn là Bênh viện đa khoa hang I với quy mô 650 giường kế hoạch, năm 2019 bệnh viện đã tiếp nhận 89.844 lượt khám bệnh ngoai trú và 40.333 lượt điều trị nội trú. Hàng năm tổng chi phí khám chữa bệnh tai bênh viên được $\mathrm{BHXH}$ thanh toán là hơn 150 tỷ đồng. Với đặc thù là bệnh viện đa khoa tuyến tỉnh miền núi phía Bắc nên mô hình bệnh tật của bệnh viện khá đa dạng, một số bệnh có tỷ lệ mắc cao trong mô hình bệnh tật tại bệnh viện năm 2018 gồm: bệnh hệ hô hấp, bệnh hệ tiểu hóa, thai nghén sinh đẻ và hậu sản, bệnh hệ tuần hoàn..., đây là những bệnh thường có thời gian nằm viện dài, chi phí tiền thuốc cao. Nghiên cứu Phân tích cớ cấu chi phí khám chữa bệnh BHYT chi trả tại bệnh viện đa khoa tỉnh Lạng Sơn năm 2019 nhằm mục tiêu mô tả cơ cấu chi phí khám chữa bệnh và tỷ lệ sử dụng các dịch vụ kỹ thuậtchi phí trung bình của một số bệnh mắc nhiều nhất để chỉ ra một số tồn tại trong chi phí 
khám chữa bệnh làm cơ sở cho việc đề xuất các biện pháp phân bổ kinh phí cho các hoạt động khám chữa bệnh có hiệu quả và kinh tế tại bệnh viện trong những năm tiếp theo.

\section{II. ĐỐI TƯợNG VÀ PHƯƠNG PHÁP NGHIÊN CỨU}

2.1 Đối tượng nghiên cứu. Toàn bộ bảng thống kê chi phí khám chữa bệnh của 35.239 bệnh nhân đến khám và điều trị nội trú tại bệnh viện đa khoa tỉnh Lạng Sơn năm 2019 lưu tại BHXH tỉnh Lang Sơn.

2.2. Phương pháp nghiên cứu: Mô tả cắt ngang

Xử lý số liệu: Tỷ trọng (tỷ lệ \%), giá trị trung bình (Mean), phân loại bệnh tật theo ICD $X^{[1]}$. phần mềm Excel, STADA.

\section{KẾT QUẢ NGHIÊN CỨU}

\subsection{Cơ cấu bệnh tật tại bệnh viện đa khoa tỉnh Lạng Sơn năm 2019.}

Bảng 3.1. Mô hinh bệnh tật tại bệnh viện đa khoa tỉnh Lạng Sơn năm 2019

\begin{tabular}{|c|c|c|c|}
\hline Chương bệnh & Mã ICD-X & T'ân suất & Tỷ lệ \% \\
\hline Thai nghén, đẻ có can thiệp và hậu sản & $000-099$ & 5.933 & 16,84 \\
\hline Bệnh hệ tiêu hóa & K00-K93 & 4.209 & 11,94 \\
\hline Chấn thương-ngộ độc & S00-T98 & 4.160 & 11,81 \\
\hline Bệnh hệ hô hấp & J00-J99 & 4.031 & 11,44 \\
\hline Bệnh hệ tuần hoàn & I00-I99 & 2.839 & 8,06 \\
\hline Bênh nhiểm trùng và ký sinh trùng & A00-B99 & 2.152 & 6,11 \\
\hline Bướu tân sinh & C00-D48 & 1.747 & 4,96 \\
\hline Bênh hê sinh duc - tiết niêu & N00-N99 & 1.684 & 4,78 \\
\hline Bệnh máu và cơ quan tạo máu & D50-D89 & 1.379 & 3,91 \\
\hline Bệnh cơ xương khớp và mô liên kết & M00-M99 & 1.260 & 3,58 \\
\hline Bệnh da và mô dưới da & L00-L99 & 963 & 2,73 \\
\hline Bệnh tai và xương chũm & $\mathrm{H} 60-\mathrm{H} 95$ & 762 & 2,16 \\
\hline Bênh lý xuất phát trong thời kỳ chu sinh & P00-P96 & 740 & 2,1 \\
\hline Bệnh mắt và phần phụ & $\mathrm{H} 00-\mathrm{H} 59$ & 663 & 1,88 \\
\hline Bệnh nội tiết, dinh dưỡng, chuyến hóa & E00-E90 & 589 & 1,67 \\
\hline $\begin{array}{c}\text { Các yếu tố ảnh hưởng đến sức khỏe } \\
\text { và tiếp xúc dịch vụ y tế }\end{array}$ & Z00-Z99 & 554 & 1,57 \\
\hline $\begin{array}{c}\text { Bất thường lâm sàng và cần lâm sàng không phân } \\
\text { loại ở phẩn khác }\end{array}$ & R00-R99 & 498 & 1,41 \\
\hline Bệnh hệ thân kinh & G00-G99 & 451 & 1,28 \\
\hline Rối loạn tâm thần, hành vi & F00-F99 & 379 & 1,08 \\
\hline Dị tât bẩm sinh & Q00-Q99 & 140 & 0,4 \\
\hline Nguyên nhân ngoại sinh của bệnh tật và tử vong & V01-Y98 & 106 & 0,3 \\
\hline Tổng cộng & & 35.239 & 100 \\
\hline
\end{tabular}

Năm 2019, bảo hiểm xã hội tỉnh Lạng Sơn đã chi trả cho 35.239 lượt bệnh nhân điều trị tại bệnh viện đa khoa tỉnh Lạng Sơn với mô hình bệnh tật của 21 chương bệnh chinh. Năm chương bệnh có tỷ lệ cao gồm: thai nghén, đẻ có can thiệp và hậu sản (5.933 lượt bệnh nhân chiếm $16,84 \%)$; bệnh hệ tiêu hóa (4.209 lượt bệnh nhân chiếm 11,94\%); chấn thương - ngộ độc (4.160 lượt bệnh nhân chiếm 11,81\%); bệnh hệ hô hấp (4.031 lượt bệnh nhân chiếm 11,44\%); bệnh hệ tuần hoàn (2.839 lượt bệnh nhân chiếm 8,06\%).

3.2. Tỷ lệ \% bệnh nhân được chỉ định dịch vụ kỹ thuật

Bảng 3.2. Tý lệ chi định các khoản mục chi phí

\begin{tabular}{|c|c|c|c|}
\hline Nội dung & $\begin{array}{c}\text { Tống Số } \\
\text { lượt KCB }\end{array}$ & $\begin{array}{c}\text { Tống lượt bệnh } \\
\text { nhân được chỉ định }\end{array}$ & $\begin{array}{c}\text { \% bệnh nhân } \\
\text { được chỉ định }\end{array}$ \\
\hline (2) & $(3)$ & $(4)$ & $(5)=(4) /(3) * 100 \%$ \\
\hline Xét nghiệm & 35.239 & 34.629 & 98,3 \\
\hline Chẩn đoán hình ảnh, thăm dò chức năng & 35.239 & 24.712 & 70,1 \\
\hline Phấu thuật, thủ thuật & 35.239 & 21.981 & 62,4 \\
\hline Vật tư y tế & 35.239 & 19.074 & 54,1 \\
\hline Thuốc, dịch truyền & 35.239 & 12.395 & 35,2 \\
\hline Truyền máu & 35.239 & 2.796 & 7,9 \\
\hline
\end{tabular}


Bệnh viện đa khoa tỉnh Lạng Sơn đã chỉ định với tỷ lệ bệnh nhân cao đối với một số nội dung như: xét nghiệm (98,3\%); chẩn đoán hình ảnh, thăm dò chức năng $(70,1 \%)$; phẫu thuật, thủ thuật $(62,4 \%)$.

\subsection{Cơ cấu chi phí khám chữa bệnh tại bệnh viện.}

Bảng 3.3: Tỷ lệ về các khoản mục chi phí khám chữa bệnh

\begin{tabular}{|c|c|c|}
\hline Nội dung chi phí & Giá trị (1000 đ) & Tỷ lệ (\%) \\
\hline Tiền giường & 51.738 .384 & 33,6 \\
\hline Phầu thuật, thủ thuật & 36.524 .676 & 23,7 \\
\hline Tiền thuốc, dịch truyền & 27.166 .693 & 17,6 \\
\hline Tiền xét nghiệm & 18.704 .377 & 12,1 \\
\hline Chẩn đoán hình ảnh, thăm dò chức năng & 7.348 .517 & 4,8 \\
\hline Máu & 6.304 .558 & 4,1 \\
\hline Vật tư y tế & 5.554 .625 & 3,6 \\
\hline Tiền khám & 777.894 & 0,5 \\
\hline Tống chi phí khám chữa bệnh & $\mathbf{1 5 4 . 1 1 9 . 7 2 6}$ & $\mathbf{1 0 0}$ \\
\hline
\end{tabular}

Năm 2019, BHXH tỉnh Lạng Sơn đã chi trả hơn 154 tỷ đồng cho bệnh viện đa khoa tỉnh Lang Sơn, trong đó tiền giường chiếm tỷ lệ cao nhất 33,6\%; tiền phẫu thuật, thủ thuật đứng thứ hai với $23,7 \%$. Tiền thuốc, dịch truyền có giá trị được chi trả chiếm $17,6 \%$.

\subsection{Chi phí trung bình/đợt điêuu trị theo loại dịch vụ kỹ thuật}

Bảng 3.4: Chi phí trung bình/đợt điều trị/bệnh nhần

\begin{tabular}{|c|c|c|c|}
\hline Nội dung & $\begin{array}{l}\text { Tổng chi phí } \\
\text { (1000 đ) }\end{array}$ & $\begin{array}{c}\text { Tổng lượt bệnh } \\
\text { nhân được chỉ } \\
\text { định }\end{array}$ & $\begin{array}{c}\text { Chi phí trung bình } \\
\text { /đợt điều trị/bệnh } \\
\text { nhân (1000 đ̂) }\end{array}$ \\
\hline (2) & (3) & $(4)$ & $(5)=(3) /(4)$ \\
\hline Tiền giường & 51.738 .384 & 35.239 & 1.468 \\
\hline Tiền phấu thuật, thủ thuật & 36.524 .685 & 21.981 & 1.662 \\
\hline Thuốc, dịch truyên & 27.166 .683 & 34.665 & 784 \\
\hline Tiền xét nghiệm & 18.704 .370 & 34.629 & 540 \\
\hline Chấn đoán hình ảnh, thăm dò chức năng & 7.348 .509 & 24.712 & 297 \\
\hline Chi phí máu & 6.304 .558 & 2.796 & 2.255 \\
\hline Vât tư y tế & 5.554 .657 & 27.702 & 201 \\
\hline Tiên công khám & 777.890 & 714 & 38 \\
\hline Công & 154.119 .726 & & \\
\hline
\end{tabular}

Xem xét chi phí trung bình/đợt điều trị đối với 1 bệnh nhân cho thấy đối với bệnh nhân có phấu thuật, thủ thuật là 1,662 triệu đồng. Chi phí tiền xét nghiệm không chênh lệch nhiều so với tiền thuốc, dịch truyền (540 nghìn so với 784 nghìn).

3.5. Mười chương bệnh có chi phí tiền thuốc trung bình/đợt điêu trị cao nhất/bệnh nhân Bảng 3.5: Mười chương bệnh có chi phí tiền thuốc cao nhất Đơn vị tính: 1000 đồng

\begin{tabular}{|c|c|c|c|}
\hline Chương bệnh & Mã ICD-X & Trung bình & Tối đa \\
\hline Bệnh hệ thần kinh & G00-G99 & 2.818 .080 & 42.856 .452 \\
\hline $\begin{array}{l}\text { Bất thường lâm sàng và cận lâm sàng } \\
\text { không phân loại ở phẩn khác }\end{array}$ & R00-R99 & .766 & 712 \\
\hline Bệnh cơ xương khớp và mô liên kết & M00-M99 & 1.638 .415 & 10.854 .913 \\
\hline Bệnh hệ tuần hoàn & I00-I99 & 1.145 .358 & 83.866 .418 \\
\hline Bệnh hệ hô hấp & J00-J99 & 1.102 .965 & 89.538 .240 \\
\hline Chấn thương - ngô đôc & S00-T98 & 1.021 .882 & 35.016 .130 \\
\hline Bướu tân sinh & C00-D48 & 931.271 & 34.426 .348 \\
\hline Bệnh hệ sinh dục - tiết niệu & N00-N99 & 864.247 & 24.525 .582 \\
\hline Bệnh hệ tiêu hóa & K00-K93 & 861.140 & 37.931 .063 \\
\hline Dị tật bẩm sinh & Q00-Q99 & 737.044 & 58.601 .226 \\
\hline
\end{tabular}

Trong 10 chương bệnh có chi phí trung bình tiền thuốc trong 1 đợt điều trị/bệnh nhân, có 3 chương bệnh thường gặp gồm: bệnh hệ thần kinh có tổng chi phí trung bình cao nhất $(2,818$ triệu đồng); bệnh hệ tuần hoàn $(1,145$ triệu đồng); bệnh hệ hô hấp (1,102 triệu đồng). 


\subsection{Mười loại thuốc có chi phí lớn nhất tại bệnh viện \\ Bảng 3.6 Mười loại thuốc bệnh viên sử dụng trong năm 2019 có chi phí lớn nhất}

Đơn vị tính: 1000 đồng

\begin{tabular}{|c|c|c|c|}
\hline $\begin{array}{l}\text { Nhóm } \\
\text { thuốc }\end{array}$ & Hoạt chất & Tên thuốc & $\begin{array}{c}\text { Tổng chi } \\
\text { phí }\end{array}$ \\
\hline \multirow{7}{*}{$\begin{array}{l}\text { Kháng } \\
\text { sinh }\end{array}$} & Ceftizoxim & Feftibiotic 1000 & 1.656 .803 \\
\hline & Ceftriaxon & $\begin{array}{c}\text { Rocephin 1G } \\
\text { I.V. }\end{array}$ & 1.249 .472 \\
\hline & Cefepim & Cefeme 1G & 929.083 \\
\hline & Tinidazol & $\begin{array}{c}\text { Sindazol } \\
\text { Intravenous }\end{array}$ & 716.285 \\
\hline & Cefotaxim & \begin{tabular}{|l|} 
Taxibiotic 1000 \\
\end{tabular} & \begin{tabular}{|l|}
632.092 \\
\end{tabular} \\
\hline & Cloxacillin & Syntarpen & 582.133 \\
\hline & $\begin{array}{c}\text { Imipenem \& } \\
\text { cilastatin }\end{array}$ & Tienam & 579.610 \\
\hline $\begin{array}{l}\text { Dịch } \\
\text { truyền }\end{array}$ & Natri clorid & $\begin{array}{c}\text { Natri clorid } \\
0,9 \%\end{array}$ & 750.091 \\
\hline \multirow{3}{*}{$\begin{array}{l}\text { Thuốc } \\
\text { giảm } \\
\text { đau }\end{array}$} & Paracetamol & $\begin{array}{c}\text { Paracetamol } \\
\text { Kabi }\end{array}$ & 539.448 \\
\hline & Aescin & $\begin{array}{c}\text { Sodium } \\
\text { Aescinate }\end{array}$ & 491.453 \\
\hline & Tống & & 8.126 .469 \\
\hline
\end{tabular}

Kháng sinh là thuốc có mặt trong danh mục 10 thuốc có chi phí cao đã được BHXH tỉnh thanh toán cho bệnh viện đa khoa tỉnh Lạng sơn bao gồm một số thuốc như: Ceftibiotic, Rocephin, Cefeme.... Thuốc giảm đau có paracetamol và dịch truyền có Natri clorid cũng được sử dụng với chi phí cao tại bệnh viện.

\section{BÀN LUÂN}

Chi phí khám chữa bệnh hợp lý tại cơ sở y tế luôn được các nhà quản lý quan tâm nhằm sử dụng hiệu quả nguồn kinh phí hiện có, trong đó chủ yếu là nguồn từ BHYT. Xem xét cơ cấu chi phí khám chữa bệnh BHYT từ nguồn dữ liệu của BHXH sẽ giúp nhà quản lý phát hiện những bất cập trong sử dụng thuốc và dịch vụ kỹ thuật tại cơ sở khám chữa bệnh.

Tại bệnh viện đa khoa tỉnh Lạng Sơn có tỷ lệ bệnh nhân được chỉ định xét nghiệm chiếm $98,3 \%$ cho thây sự cần thiết của các kết quả xét nghiệm trong việc chẩn đoán bệnh, tuy nhiên cần giám sát nhẳm tránh lạm dụng xét nghiệm trong chẩn đoán bệnh. Cở câu chi phí khám chữa bệnh tại bệnh viện đa khoa tỉnh Lạng Sơn cho thấy tỷ lệ chi phí tiền giường cao nhất chiếm $33,6 \%$, kết quả này cũng tương tự như bệnh viện đa khoa huyện Yên Châu với tỷ lệ chi phí tiền giường chiếm tỷ lê cao nhất $(40,93 \%)^{[2]}$ điêu này cho thấy thực tế là bệnh nhân đến khám và điều trị chủ yếu sẽ được chỉ định điều trị nội trú và kéo dài số ngày điều trị.

Chi phí tiền thuốc trung bình đối với 10 bệnh có chi phí cao nhất đã chỉ ra những bệnh có liên quan đến mô hình bệnh tật như: bệnh hệ thần kinh, bệnh hệ tuần hoàn và bệnh hệ hố hấp, bệnh cở xương khớp, bướu tân sinh. Để giảm chi phí điều trị của một số bênh thì rất cần sự tham gia của y tế dự phòng trong việc phòng tránh một số bệnh, ngoài ra cũng cần xem xét đến chính sách chi trả cho tầm soát một số bệnh như bướu tân sinh.

Xem xét các hoạt chất có chi phí cao tại bệnh viện đa khoa tỉnh Lạng Sơn năm 2019 gồm: 7 hoạt chất kháng sinh, dịch truyền, thuốc giảm đau. Một số kháng sinh cần được theo dõi khi sử dụng là các kháng sinh nhóm 2 theo khuyến cáo của WHO như: ceftriaxon, cefotaxim; đặc biệt là kháng sinh thuộc nhóm dự trữ theo khuyến cáo như cefepim ${ }^{[4]}$. Kết quả này khuyến nghị bệnh viện cần có chiến lược quản lý sử dụng kháng sinh, xây dựng danh mục kháng sinh cần quản lý theo các mức độ nhằm hợp lý trong sử dụng thuốc.

\section{KẾT LUÂ̂N}

Năm 2019, BHXH tỉnh Lạng Sơn đã chi trả tổng chi phí khám chữa bệnh cho bệnh viện đa khoa tỉnh hơn 154,119 tỷ đồng cho 21 chương bệnh. Tỷ lệ bệnh nhân được chỉ định xét nghiệm chiếm 98,3\%; chẩn đoán hình ảnh, thăm dò chức năng chiếm 70,1\%. Chi tiền giường chiếm cao nhất $(33,6 \%)$; tiền phẫu thuật, thủ thuật chiếm $23,7 \%$; tiên thuốc, dịch truyền chiếm 17,6\%. Ba kháng sinh có chi phí cao nhất gồm: ceftizoxime, ceftriaxon, cefepim. Bệnh viện cần tăng cường quản lý giám sát các dịch vụ kỹ thuật được chỉ định và phân loại kháng sinh theo nhóm để ưu tiên giám sát.

\section{TÀI LIÊUU THAM KHẢO}

1. Bộ Y tế (2015), Hướng dẫn sử dụng Bảng phân loại thống kê Quốc tế vê bênh tật và các vân đề sức khỏe có liên quan phiên bản lần thứ 10 (ICD $10)$, Nhà xuất bản $Y$ học, Hà Nội.

2. Nguyển Thị Thanh Hương, Mai Lương Tiến (2017), Khảo sát cơ cấu chi phí khám chữa bệnh tai bệnh viện đa khoa huyện Yên Châu, tỉnh Sớn La năm 2018, Tạp chí $Y$ học Việt Nam Số 2 tháng 3 năm 2020; trang 65-69.

3. Trung ương (2017); Nghị quyết số 20-NQ/TW ngày 25/10/2017 của Ban Chấp hành trung ương Đảng khóa XII về Tăng cường bảo vệ, chăm sóc sức khỏe nhân dân trong tình hình mới

4. WHO (2017); Model Lists of Essential Medicines (EML) $20^{\text {th }}$

5.https://baohiemxahoi.gov.vn/tintuc/Pages/hoatdong-he-thong-bao-hiem-xa hoi.aspx?CateID = 52\&ItemID $=3815$ 